\title{
Short communication: Diet-induced variations in milk fatty acid composition have minor effects on the estimated melting point of milk fat in cows, goats, and ewes: Insights from a meta-analysis
}

\author{
P. G. Toral, ${ }^{*} \dagger$ L. Bernard, ${ }^{*} \dagger$ Y. Chilliard, ${ }^{*} \dagger^{1}$ and F. Glasser ${ }^{*} \dagger$ \\ *INRA, UMR1213 Herbivores, F-63122 Saint-Genès-Champanelle, France \\ †Clermont Université, VetAgro Sup, UMR Herbivores, BP 10448, F-63000 Clermont-Ferrand, France
}

\begin{abstract}
In ruminants, the ability to maintain milk fat melting point within physiological values could play a role in the regulation of milk fat secretion when milk fatty acid (FA) composition varies, such as in response to feeding factors. However, the relationship between milk fat fluidity and changes in milk FA composition is difficult to study experimentally. A meta-analysis was therefore conducted to compare the magnitude of diet-induced variations in milk FA composition and the calculated melting point of milk FA (used as a proxy to estimate the variations in the melting point of milk fat) in 3 dairy ruminant species (cow, goat, and sheep). The coefficient of variation (CV), a scale-free measure of statistical dispersion, was used to compare the variability of criteria differing in their order of magnitude. The analysis of a database of milk FA profiles from cows, goats, and sheep fed different dietary treatments (unsupplemented diets and diets supplemented with lipids rich in oleic acid, linoleic acid, linolenic acid, or C20-22 polyunsaturated FA) revealed that the variability of the calculated melting point of milk FA was narrow (CV of $5 \%$ ) compared with the variability of milk FA percentages (CV of 18 to $72 \%$ ). The regulation of the melting point of milk fat is thus probably involved in the control of diet-induced variations in milk fat secretion. The calculated melting point of ewe milk FA was approximately $3^{\circ} \mathrm{C}$ lower than that of goats or cows across all types of diets, which might be linked to differences in milk fat content (higher in sheep) or the structure of milk triacylglycerides among these species. Lipid supplementation increased the calculated melting point of $\mathrm{C} 18 \mathrm{FA}$ in milk, whereas that of total FA was significantly reduced by supplements rich in oleic, linoleic, and linolenic acids but not C20-22 polyunsaturated FA. However, the slight effects of dietary treat-
\end{abstract}

Received August 8, 2012.

Accepted October 21, 2012.

${ }^{1}$ Corresponding author: yves.chilliard@clermont.inra.fr ments on the calculated melting point of milk FA did not differ between cows, goats, and ewes.

Key words: milk fat melting point, lipid supplement, meta-analysis

\section{Short Communication}

In ruminants, milk FA composition is greatly influenced by feeding factors, particularly by the addition of lipid supplements to the ration (Chilliard et al., 2007). In general, feeding changes induce coordinated variations in milk FA composition, as exemplified by the negative correlations between the percentages of preformed C18 FA and de novo-synthesized FA (Moate et al., 2007). However, decreases in de novo synthesis beyond a certain threshold can limit, and even prevent, increases in milk $\mathrm{C} 18$ yield, regardless of the availability of these latter FA (Glasser et al., 2008). Thus, mechanisms other than reciprocal variations in FA availability also appear to determine milk FA secretion.

In this regard, the hypothesis of a contribution of milk fat fluidity to the regulation of milk fat secretion has been proposed over the last few decades (Timmen and Patton, 1988). Because ruminants mainly absorb saturated long-chain FA from the intestine due to ruminal biohydrogenation, these species express several metabolic adaptations to decrease the melting point of milk lipids, including the synthesis de novo of short-chain FA, the lack of 16:0 elongation, the $\Delta^{9}$-desaturation of long-chain FA, and the nonrandom esterification to triacylglycerides (Chilliard et al., 2000). The relationship between milk fat fluidity and diet-induced changes in milk FA composition is difficult to study experimentally. However, it may be indirectly tested by comparing the effect of various dietary treatments on, respectively, milk FA composition and the calculated melting point of milk FA, the latter as a proxy to estimate variations in the actual melting point of milk fat.

On this basis, we hypothesized that if the ability to maintain the melting point of milk fat within physiological values plays a role in milk fat secretion when milk FA composition varies, then the estimated variations in 
the melting point of milk fat would remain lower than variations in the FA composition. The objective of this study was therefore to compare the magnitude of the variations in milk FA composition and the estimated melting point of milk fat in 3 dairy ruminant species (cow, goat, and sheep).

A database was compiled from published studies on dairy cows, goats, and ewes that reported the effect of dietary treatments (mainly lipid supplements) on milk FA profile. To ensure correct calculation of the melting point of milk FA, studies were included in the database only when they reported the percentages of individual short-chain saturated FA (4- to 10-carbon) and of the major trans-C18:1 FA. These latter criteria allowed the removal of studies that reported poorly defined FA profiles. All information from these publications was stored in a dedicated Access database (Microsoft Corp., Redmond, WA) for further use. The final database included 70 publications that corresponded to 79 experiments and 278 experimental treatments: 170 , 58, and 50 experimental treatments for cows, goats, and ewes, respectively (see list of publications in online supplementary material; http://www.journalofdairyscience.org/). These treatments were classified in 5 categories according to the main FA of the dietary lipid source: unsupplemented diets, diets supplemented with lipids rich in oleic acid (such as rapeseed or high-oleic sunflower), in linoleic acid (such as soybean, regular sunflower, and safflower), in linolenic acid (such as linseed), or in C20-22 PUFA (such as marine microalgae or fish oil). The experimental treatments involving dietary supplements rich in palmitic acid $(\mathrm{n}=8)$ and mixes of several lipid sources $(n=7)$ were not included in this analysis because of their low number.

Because the melting point of milk fat was not reported in these publications, it was estimated as the weighted sum of the melting points of the FA (Jensen and Patton, 2000). For each individual FA, the melting point was obtained from Gunstone et al. (1994) and, failing that, from the LipidBank database (http:// www.lipidbank.jp; Japanese Conference on the Biochemistry of Lipids). The melting points of the FA that were not reported in these 2 sources were evaluated from neighboring isomers. From the original data expressed in grams per $100 \mathrm{~g}$ of milk FA, we computed the molar percentages of the milk FA and subsequently calculated the sum of the melting points weighted by the respective FA molar percentages. The estimated melting points were computed for total milk FA and also for the C18 FA fraction.

A second database was compiled from published studies that reported the effect of diet on the actual melting point of milk fat together with detailed milk FA profiles. This second database was used to compare actual milk fat melting points with calculated milk FA melting points. A statistical analysis of concordance was carried out, as detailed later, on a group of 6 studies, corresponding to 19 experimental treatments (see list of publications in online supplementary material; http://www.journalofdairyscience.org). Because the melting point is defined by the technique and conditions of measurement and the reported value is specific for these (McCarthy, 2006), the concordance was very low between measured melting point of milk fat and calculated melting point of milk FA (results not shown). For this reason, we evaluated the concordance using data from diet-induced variations (expressed as percentage of variation relative to the control; 15 pairs of data) for the 2 parameters, rather than absolute values.

The CV, a scale-free measure of statistical dispersion, was chosen as the most appropriate measure to compare the variability of variables (calculated melting point of milk FA and of $\mathrm{C} 18 \mathrm{FA}$, percentages of the main FA in milk, and $\Delta^{9}$-desaturation ratio of $\mathrm{C} 18: 0$ ), which differed in their order of magnitude. The CV were computed either across the whole database or within each animal species. The $95 \%$ CI of the CV were computed (USDA Forest Products Laboratory website: http://www1.fpl.fs.fed.us/covnorm.html; Verrill and Johnson, 2007) as a means of determining whether significant differences existed among the variables studied.

In addition, the calculated melting point of milk FA and that of the C18 FA were analyzed by ANOVA using the MIXED procedure of the SAS software package (version 9.1, SAS Institute Inc., Cary, NC). The statistical model included the fixed effects of species (cow, goat, and ewe), the type of the dietary lipid supplement (unsupplemented, or rich in oleic acid, linoleic acid, linolenic acid, or C20-22 PUFA), their interaction, and the random effect of the experiment. The means were separated using the pdiff option of the LSmeans statement of the MIXED procedure (SAS Institute Inc.). Differences were declared to be significant at $P<0.05$.

The concordance between diet-induced variations in measured melting point of milk fat and in calculated melting point of milk FA was evaluated with the concordance correlation coefficient $\left(\boldsymbol{\rho}_{\mathrm{c}} ; \mathrm{Lin}, 1989\right)$, which was calculated using the statistical program MedCalc (version 12.3.0.0; MedCalc Software, Mariakerke, Belgium). The coefficient $\rho_{\mathrm{c}}$ contains a measurement of precision $(\rho$, which measures how far each observation deviates from the best-fit line) and one of accuracy $\left(C_{\mathrm{b}}\right.$, which measures how far the best-fit line deviates from the $45^{\circ}$ line through the origin) and is robust on as few as 10 pairs of data (Lin, 1989).

In the present study, the melting point of milk fat was estimated from the weighted sum of the melting points of milk FA, assuming an additivity of the 
Table 1. Mean values and coefficients of variation (\%) with the 95\% CI of the calculated melting points of total FA and $\mathrm{C} 18 \mathrm{FA}$ in milk, the percentages of the main groups of FA in milk, and $\Delta^{9}$-desaturation ratio of C18:0

\begin{tabular}{|c|c|c|}
\hline Criterion & $\begin{array}{l}\text { Mean } \\
\text { value }^{1}\end{array}$ & {$\left[\begin{array}{c}\mathrm{CV}^{1} \\
{[95 \% \mathrm{CI} \text { of } \mathrm{CV}]}\end{array}\right.$} \\
\hline Total FA melting point $\left({ }^{\circ} \mathrm{C}\right)$ & 36.4 & $5.0[4.7-5.5]$ \\
\hline C18 FA melting point $\left({ }^{\circ} \mathrm{C}\right)$ & 26.2 & $9.8[9.0-10.7]$ \\
\hline C4-C14 even-chain (\% of total FA) & 26.9 & $24.2[22.3-26.6]$ \\
\hline Total C16 ( $\%$ of total FA) & 27.1 & $18.2[16.7-19.9]$ \\
\hline Total C18 (\% of total FA) & 40.0 & $22.2[20.4-24.4]$ \\
\hline $\mathrm{C} 18: 0$ (\% of total FA) & 9.6 & $32.7[29.9-36.0]$ \\
\hline cis-C18:1 (\% of total FA) & 19.4 & $24.6[22.6-27.0]$ \\
\hline trans-C18:1 (\% of total FA) & 6.2 & $72.1[64.5-81.9]$ \\
\hline Total C18:2 (\% of total FA) & 4.1 & $42.1[38.4-46.6]$ \\
\hline Total C18:3 (\% of total FA) & 0.6 & $67.2[60.3-75.9]$ \\
\hline Odd- and branched-chain ( $\%$ of total FA) & 2.7 & $40.0[36.3-44.7]$ \\
\hline$\Delta^{9}$-Desaturation ratio of $\mathrm{C} 18: 0^{2}$ & 0.66 & $7.6[7.0-8.3]$ \\
\hline
\end{tabular}

melting points of FA in free form (Jensen and Patton, 2000), and thus did not consider the probable effects of FA esterification and the asymmetric structure of triacylglycerides (Palmquist et al., 1993; Chilliard et al., 2000). However, diet-induced changes in the melting point of milk fat measured by laboratory techniques are concordant with those calculated from their respective FA profiles, as suggested by the concordance correlation coefficient $\left(\rho_{\mathrm{c}}=0.90\right.$, with $\rho=0.97$ and $C_{\mathrm{b}}=$ 0.92), which represents only slight differences between both methods (Lin, 1989). This good agreement could be due, at least in part, to the fact that the pattern of stereospecific distribution of FA in milk triacylglycerides does not seem to change significantly in response to feeding changes or stage of lactation (Hawke and Taylor, 1995). Furthermore, the application of this method of estimation was sensitive enough to show differences between the calculated melting points of milk FA from winter-feeding and grazing-season periods in cows, goats, and ewes (on average, $-1.7^{\circ} \mathrm{C}$; Eknæs et al., 2006; Ferlay et al., 2008; Ostrovsky et al., 2009), which is consistent with the known effect of these seasonal feeding practices on the melting point of milk fat (i.e., a lower value in milks from grazing cows; Palmquist et al., 1993; Taylor and MacGibbon, 2011). Thus, this method of estimation could be a valid proxy to study the effect of changes in milk FA profile on the melting point of milk fat.

The CV of the calculated melting point of milk FA was significantly lower than that of all the other variables evaluated (as seen from the CI of the CV; Table 1), but interestingly, there were no differences between ruminant species (data not shown in tables). Overall, the $\mathrm{CV}$ of the calculated melting points was approximately $5 \%$, whereas that of milk FA percentages ranged from 18 to $25 \%$ (sum of even-chain C4-C14, total C16 and $\mathrm{C} 18$, and cis-9 C18:1) to more than 65\% (C18:3, and trans-C18:1; Table 1). Thus, the hypothesis of a contribution of the melting point of milk fat as a regulating factor of milk fat secretion seems highly probable.

The variability of the $\Delta^{9}$-desaturation ratio of C18:0 was relatively low (CV of $7.6 \%$; Table 1 ), although small changes in this parameter could play a significant role in the regulation of the melting point of ruminant milk fat because more than $50 \%$ of the C18:0, which has a melting point of $69.7^{\circ} \mathrm{C}$, is desaturated to cis-9 C18:1, which has a melting point of $16^{\circ} \mathrm{C}$ (Chilliard et al., 2000; Mosley and McGuire, 2007). In this regard, we calculated the melting point of milk FA in 2 groups of goats that differed in their $\alpha_{\mathrm{S} 1}$-casein genotype (Chilliard et al., 2006), which is associated with lower medium-chain FA and higher $\Delta^{9}$-desaturation ratios in "low" versus "high" genotypes. The lack of differences in the calculated melting points $\left(37.96\right.$ vs. $38.04^{\circ} \mathrm{C}$, respectively, for the low and high $\alpha_{S 1}$-casein gene expression level; $P>$ 0.10) supports the hypothesis of Chilliard et al. (2006) that the observed variations in the secretion of C8:0 to C12:0 FA $(-23 \%)$ were, at least in part, compensated for by changes in the $\Delta^{9}$-desaturation ratios of $\mathrm{FA}$ ( $+7 \%$ in C18:0 $\Delta^{9}$-desaturation ratio), thus allowing maintenance of the melting point of milk fat within a physiological range.

Conversely, the low CV of the calculated melting point of milk FA was accompanied by significant differences in its mean value between ruminant species (Table 2). The calculated melting point of ewe milk FA was approximately $3^{\circ} \mathrm{C}$ lower than that of goats or cows across all types of diets. Because body temperature does not differ greatly in these 3 ruminant species, the differences in calculated melting points might be linked 
Table 2. Calculated melting point $\left({ }^{\circ} \mathrm{C}\right)$ of milk FA according to ruminant species and the type of dietary lipid supplements

\begin{tabular}{|c|c|c|c|c|}
\hline $\begin{array}{l}\text { Main FA in the dietary } \\
\text { lipid supplement }\end{array}$ & Cows & Goats & Ewes & LSM \\
\hline Unsupplemented & $37.31^{\mathrm{ab}}$ & $37.91^{\mathrm{ab}}$ & $34.30^{\mathrm{ef}}$ & $36.50^{\mathrm{A}}$ \\
\hline Oleic acid & $36.59^{\mathrm{bc}}$ & $36.47^{\mathrm{bc}}$ & $33.53^{\mathrm{fg}}$ & $35.53^{\mathrm{B}}$ \\
\hline Linoleic acid & $36.56^{\mathrm{c}}$ & $36.49^{\mathrm{bc}}$ & $33.56^{\mathrm{g}}$ & $35.54^{\mathrm{B}}$ \\
\hline Linolenic acid & $36.10^{\text {cd }}$ & $35.32^{\mathrm{de}}$ & $33.08^{\mathrm{g}}$ & $34.84^{\mathrm{C}}$ \\
\hline C20-22 PUFA & $36.73^{\mathrm{bc}}$ & $37.16^{\text {abcd }}$ & $33.67^{\mathrm{fg}}$ & $35.85^{\mathrm{AB}}$ \\
\hline LSM & $36.66^{\mathrm{A}}$ & $36.67^{\mathrm{A}}$ & $33.63^{\mathrm{B}}$ & \\
\hline
\end{tabular}

to differences in milk fat concentration among them, because ewe milk has a greater fat concentration than cow or goat milk (respectively 62,35 , and $41 \mathrm{~g} / \mathrm{kg}$ ). We speculate that a lower melting point of milk fat in the ewe might be needed to maintain adequate fluidity for a high level of fat secretion. Furthermore, the existence of interspecies differences in the structure of milk triacylglycerides cannot be ruled out, which could have an effect on the melting point of milk fat (Palmquist et al., 1993) and could counteract the abovementioned differences in the calculated values.

Surprisingly, the calculated melting point of C18 FA (Table 3) was always approximately $10^{\circ} \mathrm{C}$ lower than that calculated from total milk FA (Table 2). Possible explanations are that the medium-chain saturated FA increased the melting point of milk fat (C12:0, C14:0, and $\mathrm{C} 16: 0$ have melting points of 44,54 , and $60^{\circ} \mathrm{C}$, respectively; Gunstone et al., 1994), and $\Delta^{9}$-desaturation reduced the melting point of $\mathrm{C} 18 \mathrm{FA}$, together with the very low melting point of PUFA that escape ruminal biohydrogenation (e.g., -5 and $-11^{\circ} \mathrm{C}$ for linoleic and $\alpha$-linolenic acids, respectively; Gunstone et al., 1994). The increases in the calculated melting point of $\mathrm{C} 18$ FA with lipid supplements were similar in cows, goats, and sheep (Table 3), which could be explained by, among other mechanisms, increments in the proportion of trans-C18:1 isomers in milk (Chilliard et al., 2007), which have higher melting points than their equivalent cis isomers (Gunstone et al., 1994). In other respects, the calculated melting point of total FA in the 3 species (Table 2) was only slightly reduced by supplements rich in oleic, linoleic, and linolenic acids but not by supplements rich in C20-22 PUFA, which could be attributed to the negative effects of oilseeds and plant oils, but not marine lipids, on the proportion of C12:0-C16:0 FA in milk (Chilliard et al., 2007). Overall, these results support the hypothesis that a reduction in de novo synthesis could limit milk fat yield (and sometimes induce milk fat depression), even when C18 availability is high (Glasser et al., 2008).

In conclusion, analysis of our database of milk FA profiles from 3 dairy ruminant species and different dietary treatments revealed that the variability of the calculated melting point of milk FA is narrow (CV of $5 \%$ ) compared with the variability of milk FA percentages (CV of 18 to $72 \%$ ). The regulation of the melting point of milk fat is thus probably involved in the control of diet-induced variations in milk fat secretion. The calculated melting point of milk FA is lower in sheep than in cattle or goats, which could be related to differences in either milk fat concentration or triacylglyceride structure between these species. However, the

Table 3. Calculated melting point $\left({ }^{\circ} \mathrm{C}\right)$ of the 18-carbon FA in milk fat according to ruminant species and the major FA of the dietary lipid supplements

\begin{tabular}{|c|c|c|c|c|}
\hline $\begin{array}{l}\text { Main FA in the dietary } \\
\text { lipid supplement }\end{array}$ & Cows & Goats & Ewes & LSM \\
\hline $\begin{array}{l}\text { Unsupplemented } \\
\text { Oleic acid } \\
\text { Linoleic acid } \\
\text { Linolenic acid } \\
\text { C20-22 PUFA } \\
\text { LSM }\end{array}$ & $\begin{array}{l}25.64^{\mathrm{ef}} \\
27.94^{\mathrm{abc}} \\
28.53^{\mathrm{abc}} \\
28.26^{\mathrm{abc}} \\
27.35^{\mathrm{bcd}} \\
27.54^{\mathrm{A}}\end{array}$ & $\begin{array}{l}23.37^{\text {gh }} \\
27.35^{\text {abcd }} \\
26.85^{\text {bcde }} \\
26.02^{\text {def }} \\
24.96^{\text {cdefg }} \\
25.71^{\text {B }}\end{array}$ & $\begin{array}{l}23.01^{\mathrm{h}} \\
25.37^{\text {defg }} \\
25.87^{\text {def }} \\
25.18^{\text {defg }} \\
24.71^{\text {fg }} \\
24.83^{\mathrm{B}}\end{array}$ & $\begin{array}{l}24.01^{\mathrm{C}} \\
26.89^{\mathrm{AB}} \\
27.09^{\mathrm{A}} \\
26.49^{\mathrm{AB}} \\
25.67^{\mathrm{B}}\end{array}$ \\
\hline
\end{tabular}


slight effects of dietary treatments on the calculated melting point of milk FA did not differ among cows, goats, and ewes.

\section{ACKNOWLEDGMENTS}

P. G. Toral acknowledges receipt of a postdoctoral fellowship from Fundación Alfonso Martín Escudero (Madrid, Spain).

\section{REFERENCES}

Chilliard, Y., A. Ferlay, R. M. Mansbridge, and M. Doreau. 2000. Ruminant milk fat plasticity: Nutritional control of saturated, polyunsaturated, trans and conjugated fatty acids. Ann. Zootech. 49:181-205.

Chilliard, Y., F. Glasser, A. Ferlay, L. Bernard, J. Rouel, and M Doreau. 2007. Diet, rumen biohydrogenation and nutritional quality of cow and goat milk fat. Eur. J. Lipid Sci. Technol. 109:828855 .

Chilliard, Y., J. Rouel, and C. Leroux. 2006. Goat's alpha-s1 casein genotype influences its milk fatty acid composition and delta-9 desaturation ratios. Anim. Feed Sci. Technol. 131:474-487.

Eknæs, M., K. Kolstad, H. Volden, and K. Hove. 2006. Changes in body reserves and milk quality throughout lactation in dairy goats. Small Rumin. Res. 63:1-11.

Ferlay, A., C. Agabriel, C. Sibra, C. Journal, B. Martin, and Y. Chilliard. 2008. Tanker milk variability in fatty acids according to farm feeding and husbandry practices in a French semi-mountain area. Dairy Sci. Technol. 88:193-215.

Glasser, F., A. Ferlay, M. Doreau, P. Schmidely, D. Sauvant, and Y. Chilliard. 2008. Long-chain fatty acid metabolism in dairy cows: A meta-analysis of milk fatty acid yield in relation to duodenal flows and de novo synthesis. J. Dairy Sci. 91:2771-2785.
Gunstone, F. D., J. L. Harwood, and F. B. Padley. 1994. The Lipid Handbook. 2nd ed. Chapman and Hall, New York, NY.

Hawke, T. W., and J. C. Taylor. 1995. Influence of nutritional factors on the yield, composition and physical properties of milk fat. Pages 37-88 in Advanced Dairy Chemistry. Vol. 2: Lipids. P. F. Fox, ed. Chapman and Hall, London, UK.

Jensen, R. G., and S. Patton. 2000. The effect of maternal diets on the mean melting points of human milk fatty acids. Lipids 35:11591161.

Lin, L. I. 1989. A concordance correlation-coefficient to evaluate reproducibility. Biometrics 45:255-268.

McCarthy, O. J. 2006. Characterization of milk fat and milk fat-based products. Pages 725-778 in Advanced Dairy Chemistry. Vol. 2: Lipids. 3rd ed. P. F. Fox, and P. L. H. McSweeney, ed. Springer, New York, NY.

Moate, P. J., W. Chalupa, R. C. Boston, and I. J. Lean. 2007. Milk fatty acids. I. Variation in the concentration of individual fatty acids in bovine milk. J. Dairy Sci. 90:4730-4739.

Mosley, E. E., and M. A. McGuire. 2007. Methodology for the in vivo measurement of the $\Delta 9$-desaturation of myristic, palmitic, and stearic acids in lactating dairy cattle. Lipids 42:939-945.

Ostrovsky, I., E. Pavlikova, J. Blasko, R. Gorova, R. Kubinec, M. Margetin, and L. Sojak. 2009. Variation in fatty acid composition of ewes' milk during continuous transition from dry winter to natural pasture diet. Int. Dairy J. 19:545-549.

Palmquist, D. L., A. D. Beaulieu, and D. M. Barbano. 1993. Feed and animal factors influencing milk fat composition. J. Dairy Sci. $76: 1753-1771$

Taylor, M. W., and A. K. H. MacGibbon. 2011. Triacylglycerols. Pages 665-669 in Encyclopedia of Dairy Sciences. 2nd ed. J. W. Fuquay, ed. Academic Press, San Diego, CA.

Timmen, H., and S. Patton. 1988. Milk fat globules: Fatty acid composition, size and in vivo regulation of fat liquidity. Lipids 23:685689.

Verrill, S., and R. A. Johnson. 2007. Confidence bounds and hypothesis tests for normal distribution coefficients of variation. Commun. Stat. Theory Methods 36:2187-2206. 